tors ${ }^{4}$ : the central blockade is responsible for its antidepressant effect. There is also an anticholinergic effect, which is important in treating enuresis. Finally (and of most relevance in this case) imipramine antagonises both $\mathrm{H}_{1}$ - and $\mathrm{H}_{2}$-histaminergic receptors. ${ }^{45}$

Digital vasospasm seen in Raynaud's phenomenon, and presumably acrocyanosis, has been variously ascribed to sympathetic hyperactivity or to a 'local fault' within the digital arteries. ${ }^{6}$ Lafferty et al have recently suggested that local release of histamine from mast cells may be crucial in the maintenance of digital arterial blood flow. ${ }^{6}$ Histamine acts as a vasodilator while noradrenaline from vascular sympathetic nerve endings acts to constrict digital vessels. We propose that the antihistaminic and proadrenergic properties of imipramine may promote potent digital vasospasm in susceptible individuals.

Whatever the relationship of this vasospastic phenomenon to imipramine, physicians should be alerted to this disturbing side effect of a drug that is often prescribed for childhood enuresis.

\footnotetext{
References

${ }^{1}$ Olsen T. Peripheral vascular diseases and vascular-related disease. In: Moschella SL, Hurley HI, eds. Dermatology. 2nd ed. Philadelphia: Saunders, 1985:1002.

2 Burns EC, Dunger DB, Dillon MJ. Raynaud's disease. Arch Dis Child 1985;60:537-41.

3 Appelbaum PS, Kapoor W. Imipramine-induced vasospasm: a case report. Am J Psychiatry 1983;140:913-5.

${ }^{4}$ Gilman AG, Goodman LS, Gilman A, eds. Goodman and Gilman's The pharmacological basis of therapeutics. 6th ed. New York: MacMillan, 1985:416-7.

${ }^{5}$ Edelstein EL. Antidepressant drugs. In: Dukes MNG, ed. Meyler's side effects of drugs. 9th ed. Amsterdam: Excerpta Medica, 1980:23-5.

6 Lafferty K, Roberts VC, De Trafford JC, Cotton LT. On the nature of Raynaud's phenomenon: the role of histamine. Lancet 1983;ii:313-5.
}

Correspondence to Dr RP Anderson, 43 Scarba Street, Dunedin, New Zealand.

Received 17 August 1987

\title{
Transient neonatal hyperthyroidism and maternal thyroid stimulating immunoglobulins
}

\author{
T MATSUDA, ${ }^{*} \mathrm{~T}$ MOMOI,${ }^{*} \mathrm{~K}$ AKAISHI, ${ }^{*} \mathrm{~T}$ YAGURA,$\dagger \mathrm{K}$ KASAGI, $\ddagger$ AND K ENDO $\ddagger$ \\ Departments of ${ }^{*}$ Paediatrics and $†$ Endocrinology, Tenri Hospital, Tenri, Nara, and $\ddagger$ Department of Nuclear \\ Medicine, Kyoto University Faculty of Medicine, Sakyo-ku, Kyoto, Japan
}

\begin{abstract}
SUMMARY Serum thyroid stimulating hormone binding inhibitor immunoglobulins (TBII) and thyroid stimulating antibody (TSAb) concentrations were measured in three pregnant women with hyperthyroidism and then in their infants. The results suggested that TBII concentrations in infants in the neonatal period or from mothers during the third trimester of pregnancy showed a good correlation with the development of neonatal hyperthyroidism.
\end{abstract}

It is now widely believed that the transient thyroid overactivity in infants born to mothers with hyperthyroidism is a result of the placental transfer of thyroid stimulating immunoglobulins from the mother to the infant. The immunoglobulins in the sera from some patients with Graves' disease were shown, by the radioreceptor assay system, to inhibit the binding of thyroid stimulating hormone to its receptor sites and were designated as thyroid stimulating hormone binding inhibitor immunoglo- bulins (TBII). ${ }^{1}$ It was also shown that immunoglobulins in the patient's sera stimulated the production of cyclic AMP in human thyroid tissues and were known as thyroid stimulating antibodies (TSAb). ${ }^{2}$

We studied three unrelated infants who were born to women with hyperthyroidism, and one of them developed typical transient neonatal hyperthyroidism. We measured serum TBII and TSAb concentrations in these infants and their mothers.

\section{Case reports}

Family 1 The mother developed hyperthyroidism at 26 years old when she was in her 32nd week of pregnancy. From the 34th week until delivery she had been maintained euthyroid with methimazole. A girl (3330 g) was born at 39 weeks' gestation. On the 8th day of life she was noted to be hyperactive and had developed diarrhoea. Tachycardia was noticed on the 10th day when her body weight was $3100 \mathrm{~g}$. Thyroid studies on day 8 showed that she had hyperthyroidism; she had serum concentrations of triiodothyronine, thyroxine, free thyroxine, and 
thyroid stimulating hormone of $8.6 \mathrm{nmol} / \mathrm{l}, 527.6$ $\mathrm{nmol} / \mathrm{l}, 350.8 \mathrm{pmol} / \mathrm{l}$, and $<1.0 \mathrm{mU} / \mathrm{l}$, respectively. Treatment with propylthiouracyl and Lugol's solution was started on day 13 . Her condition and thyroid function improved gradually and the treatments were stopped on day 59. Her physical and mental development and the thyroid function tests gave normal results at 10 months of age.

Family 2 The mother was first diagnosed as having hyperthyroidism at 29 years old. Two years after the diagnosis she received partial thyroidectomy because of a poor response to antithyroid drugs. After the surgery she had been maintained euthyroid with thyroxine supplement. A girl was born at 39 weeks' gestation. Her development and thyroid function were normal during 10 months of follow up.

Family 3 The mother developed hyperthyroidism at 22 years old when she was four months pregnant. Treatment was started with methimazole but she remained hyperthyroid during the rest of her pregnancy. A boy $(2590 \mathrm{~g})$ was born at 39 weeks' gestation and his thyroid function, detected in the cord blood, was normal. Thyroid hormone concentrations gradually decreased until 2 weeks of age when serum concentrations of triiodothyronine, thyroxine, and free thyroxine were $1.3 \mathrm{nmol} / \mathrm{l}$, $47.7 \mathrm{nmol}$, and $8.0 \mathrm{pmol} / \mathrm{l}$, respectively. The hormone concentrations returned to the normal ranges at 1.5 months of age without treatment. Throughout this period thyroxine binding globulin concentrations were normal and thyroid stimulating hormone concentrations were always less than $1.0 \mathrm{mU} / \mathrm{l}$. At 4 months of age his development and thyroid functions were normal.

\section{Methods}

Serum samples from the three pregnant women and their infants were stored at $-20^{\circ} \mathrm{C}$ until assayed.
During follow up some of the specimens taken at certain intervals from the same infant were combined for TBII and TSAb assays.

Serum TBII was assayed by the method of Shewring and Smith ${ }^{3}$ using a commercial kit (Japan Travenol, Japan). Serum TSAb concentrations were assayed by the method of Kasagi et al. ${ }^{4}$

\section{Results}

In the infant in family 1 who developed neonatal hyperthyroidism, both TBII and TSAb concentrations were high at birth (table 1) and gradually decreased by day 50 (table 2). The concentrations of TBII and TSAb in the mother of this infant at the third trimester of pregnancy were close to the concentrations in the neonate.

The mother in family 2 had detectable TBII and $\mathrm{TSAb}$ concentrations in the first trimester of pregnancy and the infant had detectable TSAb but undetectable TBII concentrations in the combined sera obtained on day 4 and 11 (table 1). No TSAb was detected in the infant after the neonatal period (table 2).

The mother in family 3 had detectable TBII and slightly high TSAb concentrations in the second trimester and detectable but further decreased concentration of TBII in the third trimester of

Table 2 Concentrations of TBII and TSAb in the infants of family 1 and family 2 after birth

\begin{tabular}{|c|c|c|c|c|c|c|c|}
\hline \multirow{2}{*}{$\begin{array}{l}\text { Age } \\
\text { (days) }\end{array}$} & \multicolumn{5}{|c|}{ Family 1} & \multicolumn{2}{|c|}{ Family 2} \\
\hline & 0 & $13 / 17^{*}$ & $27 / 36^{*}$ & 43 & 50 & $4 / 11^{*}$ & $18 / 25^{*}$ \\
\hline TBII & $58 \cdot 7$ & $45 \cdot 7$ & $28 \cdot 0$ & $25 \cdot 1$ & $23 \cdot 2$ & $7 \cdot 9$ & $-6 \cdot 0$ \\
\hline TSAb & $5 \cdot 3$ & 3.4 & $2 \cdot 1$ & $1 \cdot 8$ & 1.6 & 4.6 & 0 \\
\hline
\end{tabular}

Control values: TBII, $<10 \%$; TSAb, $<1.0 \mathrm{mU} / \mathrm{l}$.

${ }^{*}$ Serum samples obtained on two different days were combined for assays.

Table 1 Concentrations of TBII and TSAb in the mothers during pregnancy and their infants at birth (family 1 and 3) or neonatal period (family 2)

\begin{tabular}{|c|c|c|c|c|c|c|c|c|}
\hline \multirow[t]{3}{*}{ Family } & \multicolumn{6}{|c|}{ Mothers } & \multirow{2}{*}{\multicolumn{2}{|c|}{ Neonates }} \\
\hline & \multicolumn{2}{|c|}{$\begin{array}{l}\text { Trimester } \\
\text { Ist }\end{array}$} & \multicolumn{2}{|l|}{$2 n d$} & \multicolumn{2}{|l|}{$3 r d$} & & \\
\hline & $T B I I$ & $T S A b$ & $T B I I$ & $T S A b$ & $T B I I$ & $T S A b$ & $T B I I$ & $T S A B$ \\
\hline 1 & $*$ & $*$ & $77 \cdot 2$ & $20 \cdot 0$ & $54 \cdot 8$ & $3 \cdot 4$ & $58 \cdot 7$ & $5 \cdot 3$ \\
\hline 2 & $33 \cdot 4$ & $22 \cdot 0$ & * & * & $*$ & $*$ & $7 \cdot 9$ & $4 \cdot 6$ \\
\hline 3 & $*$ & $*$ & $20 \cdot 6$ & $1 \cdot 8$ & $12 \cdot 8$ & $1 \cdot 3$ & $-18 \cdot 6$ & 0 \\
\hline
\end{tabular}

*Assay not done.

Control values: TBII: $<10 \%$; TSAb: $<1.0 \mathrm{mU} / \mathrm{l}$. 
pregnancy. Serum of the infant in family 3 at birth had undetectable TBII and TSAb concentrations (table 1). We assume that the transient hypothyroidism in this infant was due to the suppression of secretion of thyroid stimulating hormone as the mother was hyperthyroid during the last half of her pregnancy.

\section{Discussion}

One of three unrelated infants born to mothers with hyperthyroidism developed transient neonatal hyperthyroidism. TBII and TSAb concentrations in the cord blood from this infant were high and almost the same as those in her mother during the third trimester of pregnancy. The other infant (family 2) who had high serum TSAb but normal TBII concentrations in the neonatal period did not develop hyperthyroidism and neither did the third infant (family 3) whose TBII and TSAb concentrations in the cord serum were both undetectable.

A recent study reported high concentrations of serum TBII in patients with transient neonatal hyperthyroidism but they did not measure TSAb concentrations. ${ }^{5}$ Another study showed that detectable TSAb in the mother in the third trimester was predictive for neonatal hyperthyroidism, but TBII concentrations were not measured. ${ }^{6}$

In our study TBII concentrations, but not those of TSAb, showed a good correlation with the development of neonatal hyperthyroidism and the concen- trations of TBII in the maternal sera during the third trimester of pregnancy might have predictive value in the neonatal hyperthyroidism. We think that widespread use of assays for both TBII and TSAb will clarify the pathogenesis and predictivity of transient neonatal hyperthyroidism.

\section{References}

1 Endo K, Kasagi K, Konishi J, et al. Detection and properties of TSH-binding inhibitor immunoglobulins in patients with Graves' disease and Hashimoto's thyroiditis. J Clin Endocrinol Metab 1978;46:734-9.

2 Onaya T, Kotani M, Yamada T, Ochi Y. New in vitro tests to detect the thyroid stimulator in sera from hyperthyroid patients by measuring colloid droplet formation and cyclic AMP in human thyroid slices. J Clin Endocrinol Metab 1973;36:859-66.

3 Shewring G, Smith BR; An improved radioreceptor assay for TSH receptor antibodies. Clin Endocrinol (Oxf) 1982;17: 409-17.

4 Kasagi K, Konishi J, Arai K, et al. A sensitive and practical assay for thyroid-stimulating antibodies using crude immunoglobulin fractions precipitated with polyethylene glycol. J Clin Endocrinol Metab 1986;62:855-62.

5 Teng CS, Tong TC, Hutchison JH, Yeung RTT. Thyroidstimulating immunoglobulins in neonatal Graves's disease. Arch Dis Child 1980;55:894-5.

6 Zakarija M, McKenzie M. Pregnancy-associated changes in the thyroid-stimulating antibody of Graves' disease and the relationship to neonatal hyperthyroidism. J Clin Endocrinol Metab 1983;57:1036-40.

Correspondence to Dr T Matsuda, Department of Paediatrics, Yonaha Hospital, Izumi, Kuwana, Mie, 511 Japan.

Received 7 August 1987

\title{
Severe combined immunodeficiency syndrome, tissue transplant, leukaemia, and $\mathrm{Q}$ fever
}

\author{
M M LOUDON AND E N THOMPSON
}

Department of Child Health, University of Wales College of Medicine, Cardiff, South Wales

SUMMARY A child born with severe combined immunodeficiency, who was immunoreconstituted by a fetal liver and thymus transplant, developed acute lymphoblastic leukaemia in the donor cell line. During remission she contracted acute $Q$ fever, which gave rise to unexpected complications. Early treatment of the $Q$ fever might have altered the subsequent events and prevented her death.

$Q$ fever is a sporadic infection and is an occupational hazard of men working with domestic sheep and cattle. The clinical features of the acute and chronic form in adults are well described. Reports in children are rare ${ }^{12}$ with less than 50 notifications from $1975-81 .{ }^{3}$ Heard et al reported five cases in immunocompromised adults. ${ }^{4}$ We describe a girl, who was 6 years old at the time of her death, who had been immunoreconstituted by transplantation with fetal liver and thymus at 9 months old because of severe combined immunodeficiency (SCID). Acute lymphoblastic leukaemia (ALL) subsequently developed in the donor cell line. During treatment she developed acute $Q$ fever from which she ultimately died. The advantage of co- 